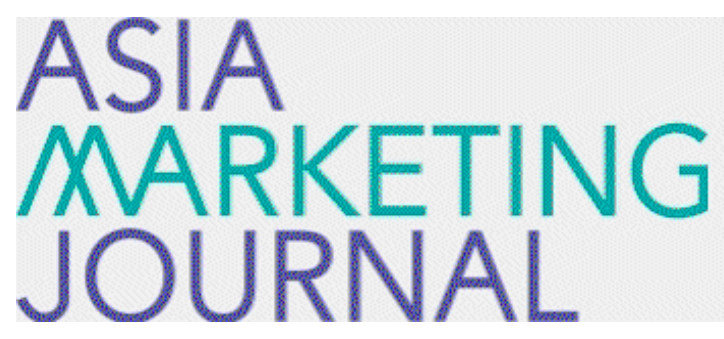

ASIA MARKETING JOURNAL

Volume 18 | Issue 3

Article 1

$10-31-2016$

\title{
Effective Demand Lifting through Pre-Launch Movie Marketing Activities
}

Tae Ho Song

Shijin Yoo

Janghyuk Lee

Follow this and additional works at: https://amj.kma.re.kr/journal

Part of the Marketing Commons

\section{Recommended Citation}

Song, Tae Ho; Yoo, Shijin; and Lee, Janghyuk (2016) "Effective Demand Lifting through Pre-Launch Movie Marketing Activities," Asia Marketing Journal: Vol. 18 : Iss. 3 , Article 1.

Available at: https://doi.org/10.15830/amj.2016.18.3.1

This Article is brought to you for free and open access by Asia Marketing Journal. It has been accepted for inclusion in Asia Marketing Journal by an authorized editor of Asia Marketing Journal. 


\title{
Effective Demand Lifting through Pre-Launch Movie Marketing Activities*
}

\author{
Tae Ho Song** \\ Shijin Yoo*** \\ Janghyuk Lee****
}

The purpose of this paper is to examine empirically how to balance advertising expenditure before and after launch with regard to the direction of word of mouth in the motion picture industry. The vector auto-regression model is applied to assess the dynamic impact of advertising and word of mouth on sales. Empirical data, including advertising, word of mouth, and sales (the number of entries) of 83 movies are used for analysis. The research results show that for a movie having more positive word of mouth in the pre- and post-launch periods, it is worthwhile to spend the advertising budget in the pre-launch period only and to spare it in post-launch period. However, it is worthwhile to spare the advertising budget in the pre-launch period for movies having less positive word of mouth before and after launch, and to concentrate spending in post-launch period instead.

Mangers who handle products and services facing shortened lifecycles, such as games, eBooks, and digital music contents, need to check the quality of pre-launch word of mouth for their advertising budget decisions in the pre- and post-launch periods and spend more of the advertising budget in the post- (pre-) launch period if pre-launch word of mouth is negative (positive). For products and services with a shortened lifecycle, it is recommended to spend more of the advertising budget in the post- (pre-) launch period if pre-launch word of mouth is negative (positive).

Key words: Word of mouth, Service lifecycle, Motion picture industry, Vector auto-regression model

This work was supported by the National Research Foundation of Korea Grant funded by the Korean Government (NRF-2013S1A5A8024569)

** School of Business, Pusan National University (thsong@pusan.ac.kr)

*** Korea University Business School (shijinyoo@korea.ac.kr), Corresponding Author

***** Korea University Business School (janglee@korea.ac.kr) 


\section{Introduction}

The fact that every movie is unique ${ }^{1)}$ and has a short lifecycle ${ }^{2)}$ creates substantial challenges for marketers involved in the motion picture industry, who must develop an innovative service every time and manage marketing activities before and after launch. To make a new movie successful, it is recommended to balance pre- and post-launch marketing activities and to integrate on- and off-line marketing activities. ${ }^{3)}$ Pre-launch activities such as market study, financial analysis, and development of service concept are reported to play a key role in the success of a new service (Ottenbacher and Harrington, 2010).

As for marketing in the pre-launch period, companies may create a micro website dedicated to the movie, as well as a Facebook fan page; upload trailer videos to YouTube and movie-related sites such as Yahoo! Movies and Rotten Tomatoes; purchase display and keyword advertising; seek publicity by appearing on well-known talk shows; and introduce the film through entertainment programs on traditional media. ${ }^{4)}$ Consumers are influenced by various pre-launch marketing activities, such as off-line premieres and consumers' word of mouth (WOM) such as online comments and ratings. In addition, movie studios heavily advertise their movies and the advertising/sales ratio (40\%) is the largest among all US industries (Schonfeld and Associates, 2006; Rennhoff and Wilbur, 2011). Therefore, it is plausible to assume that advertising is the major firm-initiated marketing activity in the movie industry. Both firminitiated marketing activities and consumergenerated WOM influence consumers' expectation levels for movies before they launch, and therefore play key roles in determining the magnitude of initial demand after launch.

Accelerated diffusion speed and widened coverage of word of mouth driven by social media and the mobile Internet tend to enhance dynamics in managing pre-launch marketing activities. In this research, we examine the different natures of pre-launch and post-launch marketing activities and explore influencing factors for the effectiveness of the pre-launch marketing activity.

1) In the United States, 534 films were released in 2010; 12 of them (2.2\%) were sequels.

2) The average run of the above movies on movie theater screens was 12 weeks.

3) The Internet Advertising Bureau (IAB) UK provides a guideline for movie marketing including buzz metric and on- and off-line integration. http://www.iabuk.net/en/1/moviemarketing.html

4) In the case of "Harry Potter," http://harrypotter.warnerbros.com (micro site), http://www.facebook.com/harrypottermovie (Facebook fan page), and http://www.youtube.com/user/harrypotter (YouTube channel). 


\section{Research Background}

Several studies have investigated the effect of pre-launch marketing activities on market performance, though few of them examine internal or external circumstances for effective pre-launch marketing activities. For example, Zufryden (1996) proposed a hierarchical behavioral model - advertising $\rightarrow$ awareness $\rightarrow$ intention $\rightarrow$ purchase behavior - to evaluate the effect of early marketing activities (e.g., advertising) on the market performance of new films. Although Zufryden's work discusses early marketing activities during the launch time, his proposed model framework provides a potentially useful tool for understanding the role of pre-launch marketing activities.

Pre-launch marketing activities may influence pre-launch expectation positively, which in turn positively affects the market performance. However, as Elberse and Anand (2007) pointed out, the effect significantly depends on the product quality. They found that the positive effect of pre-launch advertising on pre-launch expectation, measured by Hollywood Stock Exchange prices, varied strongly across the quality of the movies, resulting in negative average returns to advertising. However, they did not investigate the long-term impact of pre-launch advertising on post-launch performance, i.e., they only focused on the pre-launch market expectation rather than the actual post-launch performance.

Pre-launch marketing activities may have a negative effect due to high expectations built up prior to launch. Although it has a slightly different context, a study by Joshi and Hanssens (2009) found that box-office-hit movies may result in stock price decrease if they receive unusually high media support, lifting investors' expectations.

Chintagunta, Gopinath, and Venkataraman, (2010) and Gopinath, Chintagunta, and Venkataraman, (2013) studied market-level responsiveness to firm-generated media (prelaunch advertising) and consumer-generated media (average user rating). Although they focused on the effect of WOM's valence after controlling the advertising effect, their result showed a significant and positive effect of prelaunch advertising on market performance in the movie industry. Onishi and Manchanda (2012) extended our knowledge about the effect of pre-launch marketing on post-launch performance. They focused on the synergistic effects of blogs and advertising to investigate the short-term effect of pre-launch advertising. They found that advertising has a bigger impact on blogging activity in the pre-launch period than in the post-launch period. Xiong and Bharadwaj (2014) examined the effect of the online buzz patterns before launch on the new product performance. They showed how to manage prelease buzz dynamics to enhance new product performance. Burmester, Becker, van Heerde, 
and Clement (2015) tried to give the answer about the relationship between pre- and postlaunch publicity and advertising on new product sales. Table 1 summarizes the relevant theories and findings from previous literature related to our research hypotheses.

Our research differs from the extant literature in several ways. First of all, we focus on the differential effect between pre-launch and post-launch marketing activities. In other words, we aim to figure out when pre-launch marketing is more effective than post-launch marketing or vice versa. Although Onishi and Manchanda (2012) studied the relationship between prelaunch marketing activities and WOM to find synergistic effects, they did not consider an in- tegrated advertising strategy between pre-launch and post-launch periods in their study. Second, we consider WOM as a moderating variable in contrast with most previous studies. As WOM becomes a major information source for consumers' purchase decisions (Godes and Mayzlin, 2004), it is important for marketing practitioners to integrate it into the marketing plan before launching a service (or product). Finally, although most studies related to pre-launch marketing have focused mainly on the short-term effect of pre-launch marketing activities, we consider an over-time impact of pre-launch and post-launch marketing activities on the total demand using an econometric time series model. This provides a guideline to manage the level

〈Table 1〉 Related Literature Summary

\begin{tabular}{|c|c|c|c|c|c|c|c|c|}
\hline & Product & $\begin{array}{c}\text { Major Dependent } \\
\text { Variables }\end{array}$ & $\begin{array}{c}\text { Pre-Launch } \\
\text { Marketing } \\
\text { Action }\end{array}$ & $\begin{array}{c}\text { Pre-Launch } \\
\text { Consumer } \\
\text { Reaction }\end{array}$ & $\begin{array}{c}\text { Post-Launch } \\
\text { Marketing } \\
\text { Action }\end{array}$ & $\begin{array}{c}\text { Post-Launch } \\
\text { Consumer } \\
\text { Reaction }\end{array}$ & $\begin{array}{c}\text { Post-Launch } \\
\text { Adverting } \\
\text { Strategy } \\
\text { Comparison }\end{array}$ & $\begin{array}{c}\text { Moderating } \\
\text { Factor }\end{array}$ \\
\hline Zufryden (1996) & Movie & \# Tickets & $X$ & 0 & 0 & 0 & $X$ & $X$ \\
\hline $\begin{array}{c}\text { Elberse and Anand } \\
\text { (2007) }\end{array}$ & Movie & Expectation (HSX) & 0 & 0 & $X$ & $X$ & $X$ & 0 \\
\hline $\begin{array}{c}\text { Joshi and Hanssens } \\
\text { (2009) }\end{array}$ & Movie & Stock Prices & 0 & 0 & $X$ & 0 & $X$ & $X$ \\
\hline $\begin{array}{c}\text { Chintagunta et al. } \\
\text { (2010) }\end{array}$ & Movie & Opening-day revenue & 0 & $X$ & $X$ & 0 & $X$ & $X$ \\
\hline $\begin{array}{c}\text { Onishi and } \\
\text { Manchanda (2012) }\end{array}$ & $\begin{array}{c}\text { Movie, Cell } \\
\text { phone, Drink }\end{array}$ & $\begin{array}{c}\text { \# Blogging, Sales } \\
\text { (or \# customers) }\end{array}$ & 0 & 0 & 0 & 0 & $X$ & $X$ \\
\hline $\begin{array}{c}\text { Xiong \& Bharadwaj } \\
\text { (2014) }\end{array}$ & Video Games & Sales & $X$ & 0 & 0 & $X$ & $X$ & $X$ \\
\hline $\begin{array}{c}\text { Burnmester et al. } \\
\text { (2015) }\end{array}$ & Video Games & Sales & 0 & $X$ & 0 & $X$ & 0 & $X$ \\
\hline \begin{tabular}{c} 
This study \\
\hline
\end{tabular} & Movie & $\begin{array}{c}\text { Valence of rating, } \\
\text { \# Tickets }\end{array}$ & 0 & 0 & 0 & 0 & 0 & 0 \\
\hline
\end{tabular}


of pre-launch marketing activities.

\section{Hypotheses}

According to the relevant literature, we can infer that WOM (Zufryden, 1996), expected quality (Elberse and Anand, 2007), and/or confirmation between customer's expectation and revealed quality (Babutsidze, 2011) may moderate the effect of (pre- and post-launch) advertising on the market performance. Based on these studies, we develop a few hypotheses to test the moderating role of the pre-launch WOM (Pre-WOM, hereafter) and post-launch WOM (Post-WOM, hereafter) on the demand effect of pre-launch advertising (Pre-AD, hereafter) and that of post-launch advertising (Post$A D$, hereafter).

\subsection{The Moderating Role of Pre-WOM and Post-WOM on the Pre-AD Effect}

First, we focus on the role of Pre-WOM on the Pre-AD effect. In the pre-launch period, consumers generate WOM without physically experiencing the product, as it is not yet available. Moreover, if the product is intangible and $\mathrm{ex}^{-}$ periential (e.g., a new service such as a new movie), it is even more difficult to judge true quality before it is actually launched and experienced (Liu, 2006). Therefore, in our context,
Pre-WOM reflects the expected quality with uncertainty (Liu, 2006).

Elberse and Anand (2007) asserted that the effect of Pre-AD varied across movies of different "quality." Although they did not explain the reason for the moderating role of quality on the impact of advertising, their results show that high-quality movies benefit more from PreAD than low-quality movies. This result is partly due to the consumption-deterring aspect of advertising (Anand and Shachar, 2004), which indicates that exposures to advertising decrease the consumer's tendency to purchase promoted products that do not fit consumer tastes well. In other words, advertising to customers with low preference for that product or service can decrease his/her intention to purchase or even generate negative WOM. Furthermore, some researchers argue that intensive advertising without high objective quality creates a risk of generating overly negative WOM and decreases the likelihood of other people seeing a movie (Babutsidze, 2011).

Therefore, because Pre-WOM can reflect the subjective preference as well as expected quality, we hypothesize a synergistic relationship between Pre-AD and Pre-WOM. That is, we infer that Pre-AD with more positive Pre-WOM is more effective in terms of total demand than Pre-AD with less positive Pre-WOM as follows:

H1a: The cumulative demand effect of prelaunch advertising (Pre-AD) for $\mathrm{mov}^{-}$ 
ies with more positive pre-launch WOM (Pre-WOM) will be stronger than that for movies with less positive pre-launch WOM (Pre-WOM).

Second, we consider the moderating role of Post-WOM on the Pre-AD effect. In contrast with Pre-WOM, Post-WOM reflects the revealed true quality, since Post-WOM presents a consumer's evaluation of a product after experiencing it. For example, considering movie audiences holding relatively high expectations before release (Liu, 2006) a movie with higher Post-WOM means a higher degree of confirmation between expected quality and true quality. Furthermore, because Pre-AD generally drives high consumer expectations, the gap between expected quality and true quality for a product with poorer Post-WOM becomes larger. Based on the disconfirmation paradigm (Oliver, 1980), which predicts satisfaction to be a function of a comparison between expectations and performance, the satisfaction and post-purchase behavior of consumers with less positive PostWOM will be lower and unfavorable. Therefore, we expect that the same amount of lifted initial demand due to Pre-AD will be sustained longer when post-launch WOM is more positive. Thus, we also propose the synergistic relationship between Pre- $\mathrm{AD}$ and Post-WOM as follows.

H1b: The cumulative demand effect of prelaunch advertising (Pre-AD) for $\mathrm{mov}^{-}$ ies with more positive post-launch WOM (Post-WOM) will be stronger than that for movies with less positive post-launch WOM (Post-WOM).

\subsection{The Moderating Role of Pre-WOM and Post-WOM on the Post-AD Effect}

Marketing communication has both an indirect effect - consumers update their prior beliefs and reduce uncertainty about the true quality of the new product (informative effects of advertising) - and a direct effect - which influences preferences through goodwill accumulation (persuasive effects of advertising) (Narayanan, Manchanda and Chintagunta, 2005). Clark, Doraszelski, and Draganska, (2009) found that advertising consistently has a significant positive effect on brand awareness but no significant effect on perceived quality in mature industries. In addition, Onishi and Manchanda (2012) reported that Pre-AD spurs blogging activity (i.e., the informative role) but becomes less effective in inducing post-launch blogging activities.

Considering today's shortened lifecycles for many products (e.g., movies) and faster WOM spreads, we infer that indirect and informative effects of advertising are less likely to work after launch. Furthermore, consumers who were informed by experienced consumers after launch should not be significantly affected by informative advertising, whereas the effect of persuasive 
advertising is less dependent on the amount of information available to consumers (Clark et al, 2009). Therefore, we expect that direct and persuasive effects of advertising are more likely to work than the indirect and informative effects of advertising after launch.

Based on this point of view, we focus on the effectiveness of persuasive roles of post-launch advertising. Assuming the existence of a threshold and/or decreasing returns to the amount of advertising (Zufryden, 1996, Song et. al. 2009), we can infer that higher awareness and more favorable evaluation of a product in the early stage of product lifecycle may restrict the marginal effect of advertising. For example, a movie with more positive Pre-WOM is likely to have higher awareness and better perceived quality than a movie with less positive Pre-WOM. Because the main role of Post-AD is persuasion, we can infer that Post-AD with less positive Pre-WOM is more effective in lifting the total demand. Therefore, we propose the following:

H2a: The cumulative demand effect of postlaunch advertising (Post- $A D$ ) for movies that have less positive pre-launch WOM (Pre-WOM) will be stronger than that for movies that have more positive pre-launch WOM (Pre-WOM).

As in the case of Pre-WOM, a product with more positive Post-WOM is likely to have higher awareness and better perceived quality. Thus, we can infer that the marginal effectiveness of advertising becomes lower for such a product. Since Post-WOM is based on consumers' experiences of revealed quality, it is more difficult to lift the total demand by additional Post$\mathrm{AD}$ for products with more positive Post-WOM. Therefore, we also propose the following:

H2b: The cumulative demand effect of postlaunch advertising (Post-AD) for movies that have less positive post-launch WOM (Post-WOM) will be stronger than that for movies that have more positive post-launch WOM (Post-WOM).

\section{Model}

We test the proposed hypotheses using a demand model based on three stages: pre-launch, initial demand, and post-launch. Figure 1 shows the conceptual research framework for our modeling approach. We assume that potential demand grows with pre-launch marketing activities and WOM, and this lifted potential demand will affect the actual demand at the initial launch stage and subsequent durations. In addition, actual demand will be affected by post-launch marketing activities and WOM. We develop three models for each stage and integrate them to capture the long-term relationship among variables of interest. To consider 
〈Figure 1〉 Model Framework

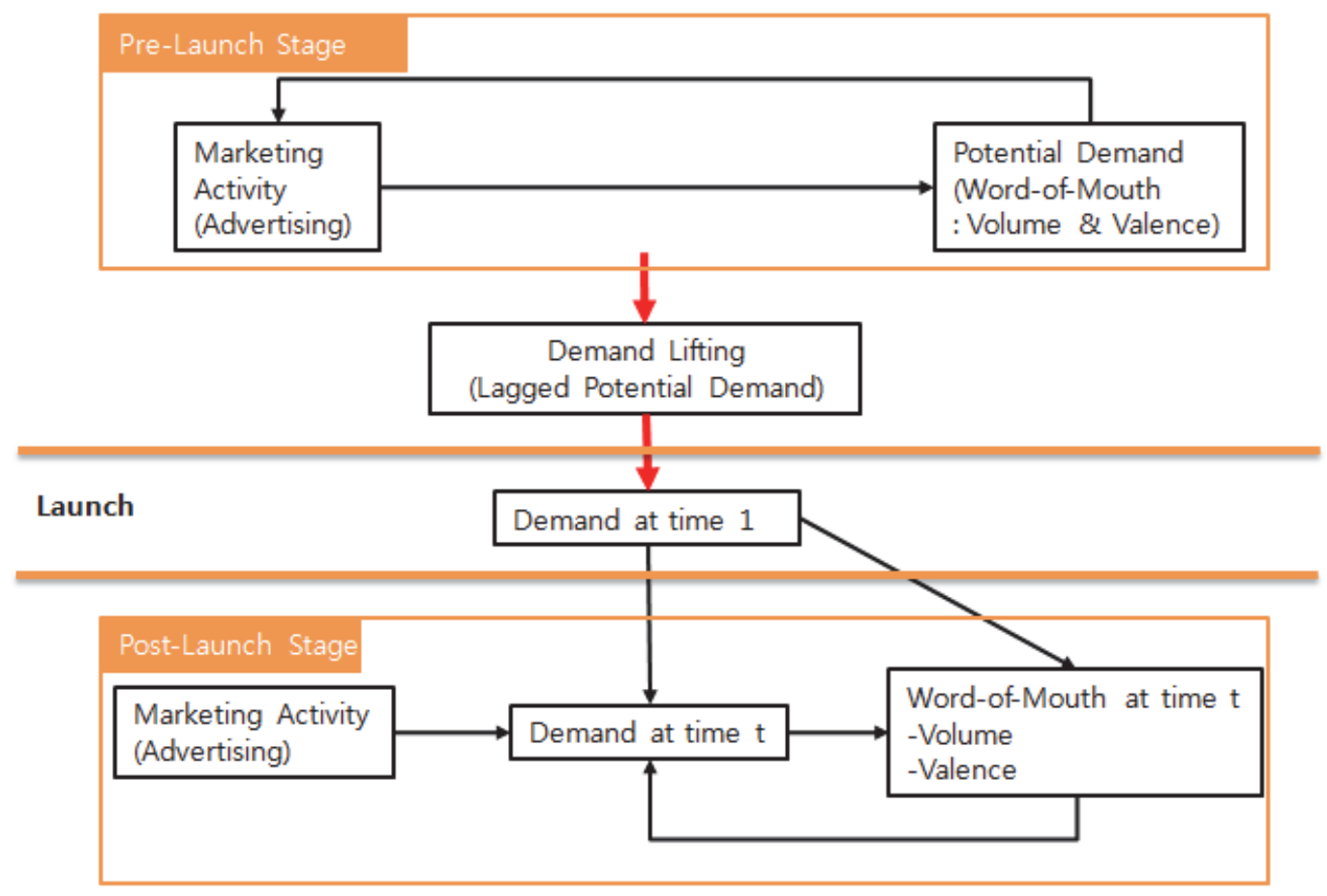

the endogenous relationship between marketing action and response/performance variables, our models utilize the vector auto-regression (VAR) model. The VAR model is a systematic approach in which each variable is treated as potentially $+\left[\begin{array}{l}\vartheta_{i, 1}^{(1)} \\ \vartheta_{i, 2}^{(1)}\end{array}\right] \times$ Weekend $_{i t}$ $+\sum_{j=1}^{p}\left[\begin{array}{ll}\beta_{i, 11}^{(1, j)} & \beta_{i, 12}^{(1, j)} \\ \beta_{i, 21}^{(1, j)} & \beta_{i, 22}^{(1, j)}\end{array}\right]\left[\begin{array}{c}\operatorname{preAD}_{i, t-j} \\ \text { preWOM }_{i, t-j}\end{array}\right]+\left[\begin{array}{c}\varepsilon_{i, 1}^{(1)} \\ \varepsilon_{i, 2}^{(1)}\end{array}\right]$ endogenous and dynamic interactions among endogenous variables is considered (Pauwels, Silva-Risso, Srinivasan, and Hanssens, 2004).

First, for the pre-launch stage, we consider a vector auto-regression (VAR) system for product or service $i$ at time $t$ with a lag order of $p$ such that:

$$
\left[\begin{array}{c}
\operatorname{preAD}_{i t} \\
\text { preWOM }_{i t}
\end{array}\right]=\left[\begin{array}{c}
\alpha_{i, 1}^{(1)} \\
\alpha_{i, 2}^{(1)}
\end{array}\right]+\left[\begin{array}{c}
\eta_{i, 1}^{(1)} \\
\eta_{i, 2}^{(1)}
\end{array}\right] \times \text { Trend }_{i t}
$$

where pre $A D$ represents Pre-AD; preWOM represents Pre-WOM; and Trend and Weekend represent deterministic trend and seasonality, respectively, to control for typical diffusion patterns in the movie industry (Gopinath et al. 2013; Onishi and Manchanda 2012). Both WOM and advertising are treated as endogenous variables considering a feedback loop between these two. For example, high advertising spending may create more WOM, which in 
turn affects future advertising decisions (Dekimpe and Hanssens, 1995). Although there are many kinds of marketing activities, we choose the advertising amount for the marketing activity because advertising is one of the most prevalent marketing tools in new product/service diffusion (Caves, 2001). Previous studies have regarded various types of customer expectation (e.g., simulated market performance, number of blogs) as potential demand (Elberse and Anand, 2007; Onishi and Manchanda, 2012). As a result, for example, the impulse response function of Pre-WOM to the shock of Pre-AD can quantify the over-time effect of pre-launch marketing activities on potential demand.

After the launch of a new product, a part of this lifted potential demand will be realized over time, and the real quality of the product will be experienced and judged by customers, resulting in Post-WOM. Firms also implement post-launch marketing activities (e.g., advertising) to increase the total demand. To capture this phenomenon, we separately model the initial launch period from the post-launch stage. Since the initial demand is strongly and directly affected by the lifted potential demand, we set up initial demand as a function of pre- launch marketing activities and WOM such that:

$$
\begin{aligned}
y_{i, 1}= & \theta_{0}+\theta_{1}\left(\sum_{t=1}^{t l_{i}} \operatorname{preWOM}_{i}(t)\right) \\
& +\theta_{2}\left(\sum_{t=1}^{t l_{i}} \operatorname{preAD}_{i}(t)\right)+\Theta \cdot X_{i}+\omega_{i}
\end{aligned}
$$

where $y_{i, 1}$ stands for initial demand for movie $i, t l_{i}$ stands for the duration of marketing activities during the pre-launch stage, and $X_{i}$ stands for covariates (number of screens on the opening day, Hollywood/non Hollywood movie, and genre) for movie $i$. Equation 2 examines how the cumulative pre-launch activities (advertising and WOM) affect the initial demand.

Finally, we consider a VAR model for the post-launch stage similar to pre-launch stage such that:

$$
\begin{aligned}
& {\left[\begin{array}{c}
\operatorname{postAD}_{i t} \\
\text { postWOM }_{i t} \\
y_{i t}
\end{array}\right]=\left[\begin{array}{c}
\alpha_{i, 1}^{(2)} \\
\alpha_{i, 2}^{(2)} \\
\alpha_{i, 3}^{(2)}
\end{array}\right]+\left[\begin{array}{c}
\eta_{i, 1}^{(2)} \\
\eta_{i, 2}^{(2)} \\
\eta_{i, 3}^{(2)}
\end{array}\right] \times \text { Trend }_{i t}} \\
& +\left[\begin{array}{l}
\vartheta_{i, 1}^{(2)} \\
\vartheta_{i, 2}^{(2)} \\
\vartheta_{i, 3}^{(2)}
\end{array}\right] \times \text { Weekend }_{i t} \\
& +\sum_{j=1}^{p}\left[\begin{array}{ccc}
\beta_{i, 11}^{(2, j)} & \beta_{i, 12}^{(2, j)} & \beta_{i, 13}^{(2, j)} \\
\beta_{i, 21}^{(2, j)} & \beta_{i, 22}^{(2, j)} & \beta_{i, 23}^{(2, j)} \\
\beta_{i, 31}^{(2, j)} & \beta_{i, 32}^{(2, j)} & \beta_{i, 13}^{(2, j)}
\end{array}\right]\left[\begin{array}{c}
\operatorname{postAd}_{i, t-j} \\
\operatorname{postWOM}_{i, t-j} \\
y_{i, t-j}
\end{array}\right] \\
& +\left[\begin{array}{c}
\varepsilon_{i, 1}^{(2)} \\
\varepsilon_{i, 2}^{(2)} \\
\varepsilon_{i, 3}^{(2)}
\end{array}\right]
\end{aligned}
$$

where $y_{i, t}$ stands for demand for product $i$ at time $t$.

To test our hypothesis, we split the observed products into two groups depending on the level of positive Pre-WOM and the level of positive Post-WOM. Then, we compare the long-term effect of advertising shock at the 
pre-launch stage and that at the post-launch stage using a t-test.

\section{Data}

Our data set consists of 83 movies released between 2006 and 2007 in South Korea. We use the data for movies with 50,000 attendances or more, at least 30 days of pre-launch period, and no less than 20 screening days to include the commercial and fully advertised movies only. Among our 83 selected movies, there are 37 domestic movies and 46 foreign movies, and 37 Hollywood movies and 46 nonHollywood movies. Table 2 shows the descriptive statistics for the key variables.

We collected the attendance data from the Korea Movie Database (KDB), which manages daily attendance from most of the theaters in Korea. Movies selected for this study accom- modated approximately 830,000 attendees (min. $=60,000$, max. $=4,000,000)$. Average screening days were about one month and ranged from 20 days to 75 days.

Our advertising measure includes TV, cable, newspapers, and magazines at a daily level. We note that $76 \%$ of total advertising budget is spent at the pre-launch stage, with high variance as presented in Table 2. Following several previous studies that regard consumers' online reviews and ratings as WOM behavior (e.g., Chevalier and Mayzlin, 2006; Liu, 2006; Dellarocas, Zhang, and Awad, 2007), we collected the rated movie reviews to measure WOM from naver.com, the largest portal site in South Korea. This portal site manages user-generated reviews and 10-scale evaluation ratings of each movie at a daily level and generates an average rating per movie, like Yahoo! Movies. On average, the number of reviews at the postlaunch stage is greater than that at the prelaunch stage (1,334 versus 149), and the aver-

〈Table 2〉 Descriptive Statistics

\begin{tabular}{ccc}
\hline & Average & Std \\
\hline Unit Sales (person) & 823,240 & 707,809 \\
Entire runs (days) & 28 & 10 \\
Advertising budget at pre-launch $(\$)$ & $325,413(76 \%)$ & 223,135 \\
Advertising budget at post-launch (\$) & $102,212(24 \%)$ & 92,207 \\
WOM duration at pre-launch (days) & 104 & 118 \\
WOM star rating at pre-launch & 8.69 & 0.87 \\
Number of WOM mentions at pre-launch & 149 & 155 \\
WOM star rating at post-launch & 7.31 & 1.21 \\
Number of WOM mentions at post-launch & 1,334 & 1,415 \\
\hline
\end{tabular}


age rating at the post-launch stage is lower than the average rating at the pre-launch stage (7.31 versus 8.69). This means that many customers are less satisfied than they expected to be after watching movies - a significant gap between expectation and confirmation.

We also recognize the long duration (104 days) of WOM activity before launch on average. To consider both the volume and valence of the WOM, we operationalized the difference between the number of positive (i.e., higher than average) WOM mentions and the number of negative (i.e., lower than average) WOM mentions as the measurement of WOM. Figure 2 depicts the time series of the movie demand, advertising, and WOM for a sample movie -

〈Figure 2〉 Movie Demand, Advertising, and Word-of-Mouth for "Pirates of The Caribbean: Dead Man's Chest"

(Total unit sales: 3,932,502; advertising budget: \$ 730,328; number of pre-launch WOM mentions: 756; number of post-launch WOM mentions: 7,438; running time: 35 days)

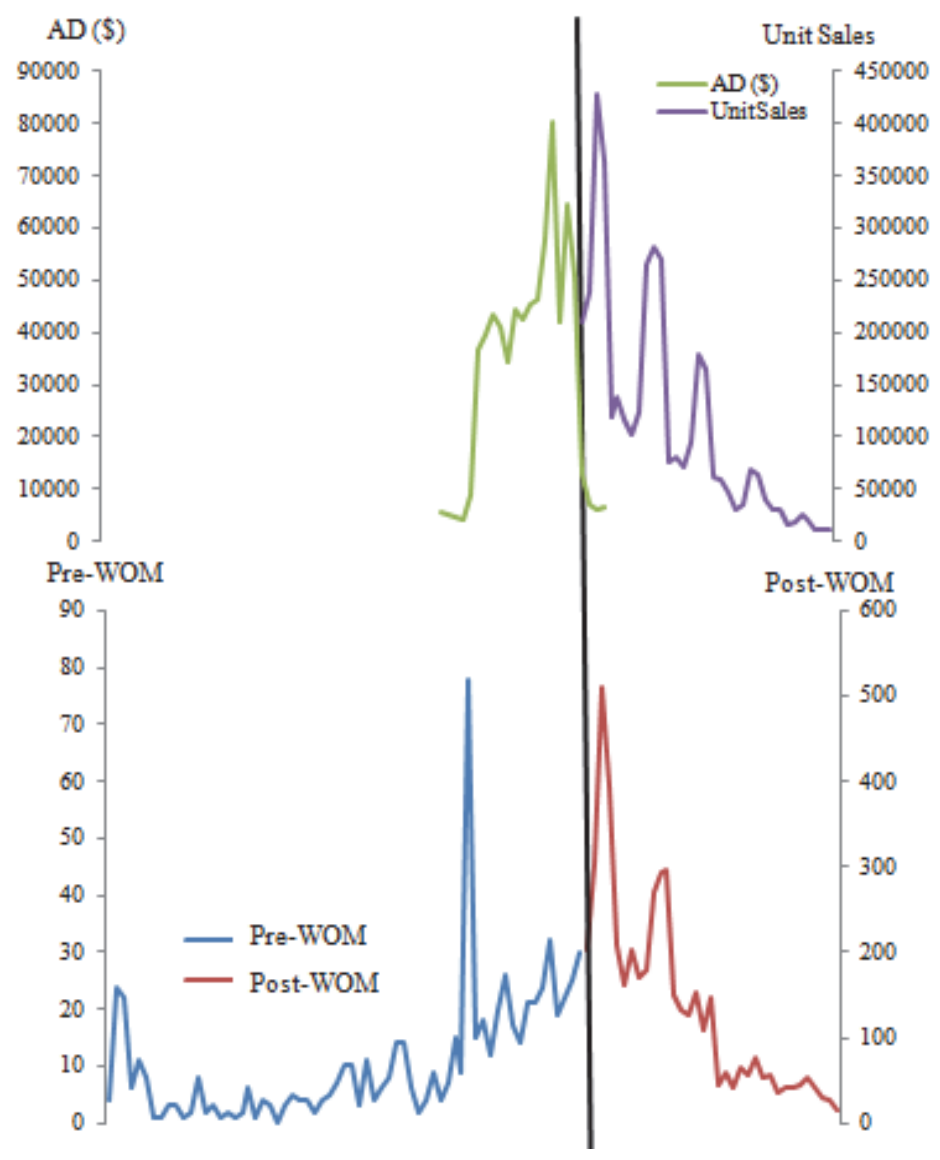


"Pirates of the Caribbean: Dead Man's Chest."

\section{Results}

First, we examined the current advertising expenditure across the WOM valences to observe the marketing decision patterns of film companies. By performing several t-tests for advertising expenditure, we confirmed that WOM valences (pre-WOM and post-WOM) usually do not affect advertising expenditure before and after launch. However, the WOM valence before launch (pre-WOM) can influence advertising expenditure only after launch (post-AD: 131,515 - positive vs. 86,264 - negative: p-value $=0.044)$. This implies that a higher anticipated expectation of a movie (pre-WOM) leads to a larger post-AD allocation. In other words, film companies may decide their marketing action depending on the marketing expectation. Finally, we can conclude that advertising is partially related to WOM and that our VAR model specification is an appropriate approach for this circumstance. Next, we analyze and compare the effectiveness of the demand effect of advertising and WOM's role in the pre- and post-launch stages.

To specify a VAR system, we test the stationarity of endogenous variables using the augmented Dickey-Fuller (ADF) test and the Kwiatkowski-Phillips-Schmidt-Shin (KPSS) test (Pauwels and Weiss, 2008). Both tests reveal that all endogenous variables have unit root and are non-stationary. Because the VAR model is estimated in first differences in case of unit-root series, we estimate our model with the evolving endogenous variables in differences (Pauwels, 2004: Srinivasan, Pauwels, Hanssens, and Dekimpe, 2004).

In addition, we select the optimal number of lags using the Bayesian information criterion for our models in the pre-launch and post-launch stages of all movies. Table 3 shows the average model fit of all models. Average $R^{2}$ ranges from 0.138 to 0.792 for the pre-launch stage and from 0.190 to 0.576 for the post-launch stage. Because our models are based on the difference of variables, these model fits are acceptable compared to other models in previous studies (e.g., Joshi and Hanssens, 2010).

$\langle$ Table 3〉 Model Fit

\begin{tabular}{cccc}
\hline Stage & \multicolumn{3}{c}{$R^{2}$} \\
\cline { 2 - 4 } & MEAN & MIN & MAX \\
\hline Pre-Launch Stage & 0.438 & 0.138 & 0.792 \\
Initial Demand & 0.538 & - & - \\
VAR at Post-Launch Stage & 0.482 & 0.190 & 0.576 \\
\hline
\end{tabular}


To test our hypotheses, we perform the Impulsive Response Function (IRF) analysis where we adjust the allocations for Pre-AD and Post- $\mathrm{AD}$ within the constant advertising budget. Specifically, for the Pre-AD condition, the Pre-AD amount is increased by $50 \%$ of the total advertising budget and the Post-AD amount is decreased by the same amount. In contrast, for the Post-AD condition, the Pre$\mathrm{AD}$ amount is decreased by $50 \%$ of the total advertising budget and the Post-AD amount is increased by the same amount. Therefore, the total advertising budget after adjustments is the same as before. We calculate and apply the impulsive shocks reflecting these adjusted advertising budgets in our IRF analysis. Finally, we compare the cumulative demand in the adjusted conditions (Pre-AD condition and PostAd condition) to that in the normal condition where the advertising allocation is not adjusted.

Figure 3 presents the results showing the moderating role of WOM on the long-term $\mathrm{Cu}^{-}$ mulative effect of advertising based on our IRF analysis. As indicated in Figure 3, we find that the Pre-AD condition for the movies with more positive Pre-WOM induces larger cumulative demand lifting than that for the movies with less positive Pre-WOM (606,309 vs. -46,089, $\mathrm{p}<.01)$. In addition, the Pre-AD condition for the movies with more positive Post-WOM also induces larger cumulative demand increasing than that for the movies with less positive PostWOM $(595,567$ vs. $32,942, p<.01)$. Because the Pre-AD condition represents greater Pre$\mathrm{AD}$ effort within a constant total advertising budget, the cumulative demand difference for the Pre-AD condition is positively affected by increased Pre-AD effort. Thus, H1a and H1b are supported.

In contrast, the Post-AD condition for the movies with less positive Pre-WOM has a greater impact on the long-term cumulative demand than that for the movies with more positive Pre-WOM $(-401,439$ vs. 917,044, $\mathrm{p}<.01)$. Likewise, the Post-AD condition for the movies with less positive Pre-WOM also has a greater impact on long-term cumulative demand than that for the movies with more positive Pre-WOM (-362,720 vs. 738,133, $\mathrm{p}<.01)$. Because the Post-AD condition represents greater Post-AD effort within a constant total advertising budget, the cumulative demand difference for the Post-AD condition is positively affected by increased Post-AD effort. Thus, H2a and H2b are supported as well.

In addition, our findings show the risk of relative negative impact of advertising on unit sales in case of mismatch with WOM. Relative negative impact may arise in cases of spending on Pre-AD for movies with less positive PreWOM, and on Post-AD for movies with more positive WOM. This means that advertising a movie with low quality (less positive WOM) may backfire on sales because advertising contrasted by less positive WOM in the pre-launch period can serve as a very negative signal for 
〈Figure 3〉 The Moderating Role of Word-of-Mouth on the Demand Effect of Advertising

$\langle$ Pre-AD Condition〉

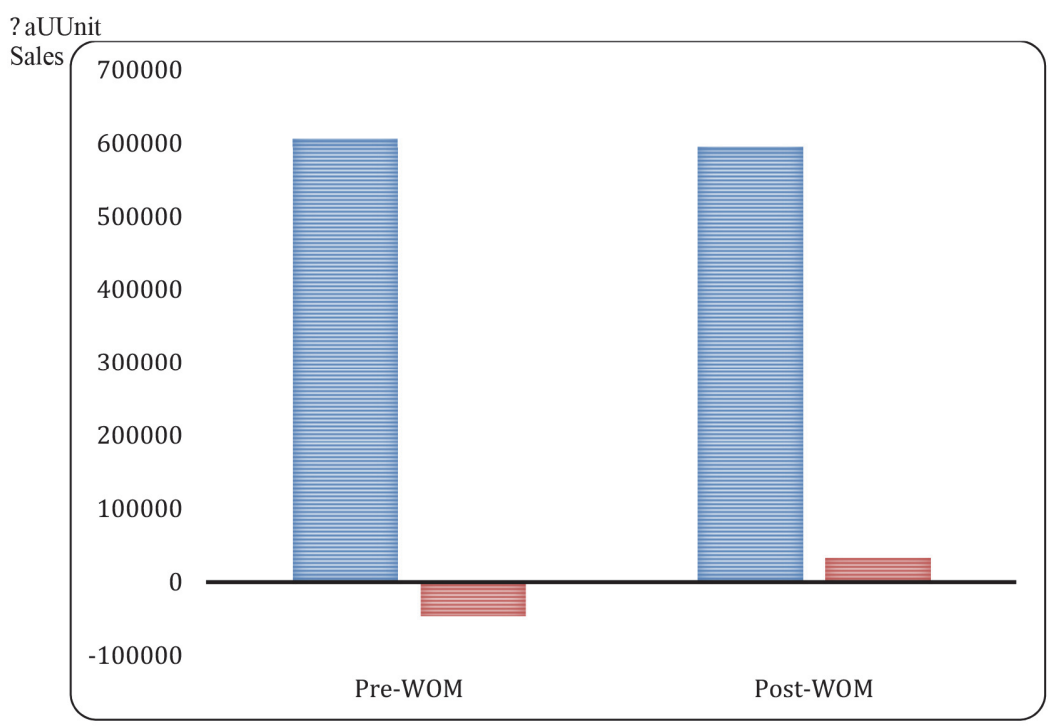

〈Post-AD Condition〉

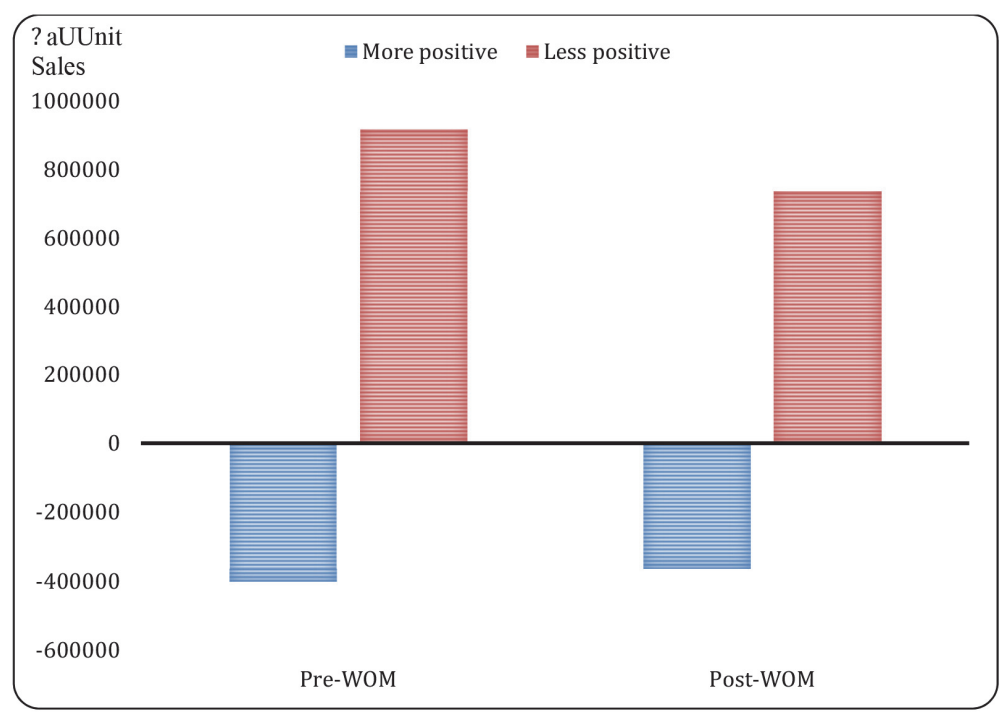

prospective viewers. On the other hand, it is not necessary to spend on advertising in the post-launch period if WOM is positive, as too much advertising can lower efficiency due to saturation and provide a confusing signal for prospective viewers. 


\section{Managerial Implications and Discussion}

In the previous section, our VAR model results demonstrate advertising effects with regard to the level of WOM. For a movie with more positive WOM in the pre- and post-launch periods, it is worthwhile to spend the advertising budget in the pre-launch period only and to spare it in the post-launch period. However, it is worthwhile to spare the advertising budget in the pre-launch period for movies having less positive WOM before and after launch and instead to concentrate spending in the postlaunch period. This opposed advertising effect can be explained by the synergy effect in the pre-launch period and by the compensatory effect in the post-launch period. In the pre-launch period, advertising can create a virtuous circle for movies having more positive WOM, as consumers' positive expectations can be confirmed by advertising while consumers cannot verify the true quality of movie. However, in the postlaunch period, as the quality of the movie is revealed, it is necessary for movies with less positive WOM to spend on advertising in order to compensate for a sales decrease due to low consumer ratings.

Our findings sharpen the advertising effectiveness with regard to the level of WOM. Common practice in the motion picture industry is to allocate more of the budget to the pre-launch period than to the post-launch period. In our data, on average, companies spent $77 \%$ of their marketing budget in the pre-launch period. Managing pre-launch marketing activities is not straightforward. For movies having more (less) positive WOM, it is recommended to allocate more budget to the pre- (post-) launch period to maximize the synergy (compensatory) effects of advertising. Our finding is consistent with Elberse and Anand (2007)'s result that shows the effect of pre-launch advertising on the market expectation depends on the quality of the movie and extends their finding by providing actual market performance data.

Our VAR model contains a couple of limitations that can be addressed in future research. First, it is separated into the pre- and postlaunch periods. As a result, it cannot provide an optimal amount of advertising spending in the pre- and post-launch periods. It only $\mathrm{rec}^{-}$ ommends whether to allocate more or less of the budget to the pre-launch period. Second, demand lifting by pre-launch marketing activities is modeled only in a single period (the first period) after launch, even though lifted demand can be spread across several periods after launch. (Bemmaor, 1994) Finally, our model aggregates data and provide results on an aggregate level. It is necessary to extend our model to provide individual-level results for movie-specific advertising budget decision making with an ex$^{-}$ tension to analyzing the content of WOM, such as whether Twitter messages contain ad-related 
materials and how widely and quickly mentions spread to prospective viewers. Notably, although we consider advertising as the major marketing activity of the movie industry, in the real world, various marketing activities have been implemented regardless of their intensity. To investigate the differential effects among various marketing activities, other major marketing activities should be considered in future research. Finally, both demand and profitability are important issues for the marketing academia. In the future, we intend to expand our research to include both the demand and profitability perspectives.

Our research focuses on explaining the advertising effect in the pre- and post-launch periods with regard to the level of WOM in the motion picture industry. Our research provides useful tips for marketing managers who have to optimize spending on pre- and postlaunch marketing activities, notably advertising, and monitor customer reviews. Even though the motion picture industry is considered a special case, findings for this industry provide useful insight for marketers in general as product lifecycles shorten and WOM spreads quickly and widely, mainly due to the rapid penetration of social media and fast fixed and mobile Internet connections such as the $4 \mathrm{G}$ mobile network. In the game and contents industries, such as books and music, the phenomenon of shortened product lifecycle is prevalent. First, advertising needs to be aligned with WOM. If WOM is positive in the pre-launch period, companies should spend more of the advertising budget in the pre-launch period than in the post-launch period. On the other hand, they should spend more in the postlaunch period if WOM is less positive. Second, it is recommended to manage customer expectations in the pre-launch period in order to avoid too much negative disconfirmation in the postlaunch period. The negative effect of advertising in the pre-launch period for movies with less positive WOM confirms previous findings (Elberse and Anand, 2007). Finally, our findings pave the way for future research to optimize advertising spending along with spreading WOM and determining its direction. We expect findings from other industries for to align with the empirical generalization of our findings.

〈Received December 28. 2015〉

〈Revised April 7. 2016〉

$\langle$ Accepted April 11. 2016〉

\section{References}

Anand, B., and Shachar, R. (2004), "Advertising the matchmaker," working paper, Harvard University Cambridge.

Babutsidze, Z. (2011), "Advertising and WordOf-Mouth in Motion Picture Industry," working paper, OFCE Sciences Po and SKEMA Business School.

Bemmaor, A. C. (1994), "Modeling the diffusion 
of new durable goods: Word-of-mouth effect versus consumer heterogeneity," In Laurent, G., Lilien, G. L., and Pras, B. (Eds.), Research Traditions in Marketing, 201-223.

Burmester, A. B., Becker, J. U., van Heerde, H. J., and Clement, M. (2015), "The Impact of Pre $^{-}$and Post-launch Publicity and Advertising on New Product Sales," International Journal of Research in Marketing, 32 (4), 408-417.

Caves, R. E. (2001), "Creative Industries: Contracts Between Art and Commerce," Cambridge, MA: Harvard University Press.

Chevalier, J. A., and Mayzlin, D. (2006), "The effect of word of mouth on sales: Online book Reviews," Journal of Marketing Research, 43 (3), 345-54.

Chintagunta, P. K., Gopinath, S., and Venkataraman, S. (2010), "The effects of online user reviews on movie box office performance: Accounting for sequential rollout and aggregation across local markets," Marketing Science, 29 (5), 944-57.

Clark, C. R., Doraszelski, U., and Draganska, M. (2009), "The effect of advertising on brand awareness and perceived quality: An empirical investigation using panel data," Quantitative Marketing and Economics, 7, 20736.

Dekimpe, M. G., and Hanssens, D. M. (1995), "The persistence of marketing effects on sales," Marketing Science, 14 (1), 1-21.

Dellarocas, C., Zhang, X. Q. and Awad, N. F.
(2007), "Exploring the value of online product reviews in forecasting sales: The case of motion pictures," Journal of Interactive Marketing, 21 (4), 23-45.

Elberse, A. and Anand, B. N. (2007), "The effectiveness of pre-release advertising for motion pictures: An empirical investigation using a simulated market," Information Economics and Policy, 19 (3-4), 319-43.

Godes, D. and Mayzlin, D. (2004), "Using online conversations to study word-of-mouth communication," Marketing Science, 23 (4), $545-60$.

Gopinath, S., Chintagunta, P. K. and Venkataraman, S. (2013), "Blogs, Advertising, and Localmarket Movie Box Office Performance," Management Science, 59 (12), 2635-2654.

Joshi, A. and Hanssens, D. M. (2009), "Movie advertising and the stock market valuation of studios: A case of Great Expectations?," Marketing Science, 28 (2), 239-50.

Joshi, A. and Hanssens, D. M. (2010), "The direct and indirect effects of advertising spending on firm value," Journal of Marketing, 74 (1), 20-33.

Liu, Y. (2006), "Word of mouth for movies: Its dynamics and impact on box office revenue," Journal of Marketing, 70 (3), 74-89.

Narayanan, S., Manchanda, P. and Chintagunta, P. K. (2005), “Temporal differences in the role of marketing communication in new product categories," Journal of Marketing Research, 42, 278-90. 
Oliver, R. L. (1980), “A cognitive model of the antecedents and consequences of satisfaction decisions," Journal of Marketing Research, 17, 460-9.

Onishi, H. and Manchanda, P. (2012), "Marketing activity, blogging and sales," International Journal of Research in Marketing, 29 (3), 221-234.

Ottenbacher, M. C. and Harrington, R. F. (2010), "Strategies for achieving success for innovative versus incremental new services," Journal of Services Marketing, 24 (1), 3-15.

Pauwels, K. (2004), “How dynamic consumer response, competitor response, company support, and company inertia shape longterm marketing effectiveness," Marketing Science, 23 (4), 596-610.

Pauwels, K., Silva-Risso, J., Srinivasan, S. and Hanssens, D. M. (2004), “New Products, Sales Promotions, and Firm Value: The Case of the Automobile Industry," Journal of Marketing, 68 (4), 142-156.

Pauwels, K. and Weiss, A. (2008), “Moving from free to fee: How online firms market to change their business model successfully,"
Journal of Marketing, 72 (3), 14-31.

Rennhoff, A. D. and Wilbur, K. C. (2011), "The Effectiveness of Post-release Movie Advertising," International Journal of Advertising, 30 (2), 305-328.

Schonfeld and Associates. (2006), “Advertising Ratios and Budgets," Schonfeld and $A^{-}$ sociates Inc.

Song, T. H., Kim, J. and Ko, W. (2009) "ReConsidering Aggregated Data Bias by Extending Koyck Model," Journal of the Korean Operations Research and Management Science Society, 34 (2), 91-100.

Srinivasan, S., Pauwels, K., Hanssens, D. M. and Dekimpe, M. G. (2004), "Do promotions benefit manufacturers, retailers, or both?," Management Science, 50 (5), 617-629.

Xiong, G. and Bharadwaj, S. (2014), "Prerelease Buzz Evolution Patterns and New Product Performance," Marketing Science, 33 (3), 401-421.

Zufryden, F. S. (1996), "Linking advertising to box office performance of new film releases - A marketing planning model," Journal of Advertising Research, 36, 29-41 